\title{
NILAI PENDIDIKAN SOSIAL KEBERAGAMAAN ISLAM DALAM MODERASI BERAGAMA DI INDONESIA
}

\author{
Tahtimatur Rizkiyah \\ Madrasah Tsanawiyah Tholabuddin Warungasem Batang \\ tahtimaturrizkiyah@gmail.com \\ Nurul Istiani \\ Institut Agama Islam Negeri Pekalongan \\ n_istiani@ymail.com
}

\begin{abstract}
ABSTRAK
Kasus radikalisme dan terorisme atas nama agama di Indonesia yang tidak kunjung usai meniscayakan pentingnya objektifikasi nilai-nilai sosial keberagamaan yang moderat. Penelitian ini bertujuan untuk mengidentifikasi nilai-nilai pendidikan sosial keberagamaan Islam dalam indikator moderasi beragama yang dirumuskan oleh Kementerian Agama Republik Indonesia. Penlitian pusataka ini menggunakan pendekatan normatif-filosofis dengan teori analisis berupa paradigma Ilmu Sosial Profetik yang dicetuskan Kuntowijoyo. Hasil penelitian menunjukan terdapat nilai sosial keberagamaan Islam dalam empat indikator moderasi beragama tersebut. Pertama, nilai transendensi dalam pendidikan toleransi berupa pembentukan pola pikir dan sikap sosial, baik dalam konteks kehidupan antar umat beragama maupun intra agama. Kedua, nilai humanisasi dalam pendidikan komitmen kebangsaan dan akomodatif terhadap budaya lokal berupa pembentukan pola pikir dan sikap menjaga nasionalisme dan kearifan lokal yang majemuk. Ketiga, nilai liberasi dalam pendidikan anti radikalisme berupa pembentukan pola pikir dan sikap yang produktif dalam mewujudkan kehidupan yang aman dan damai. Implikasi teoritik temuan ini menunjukan terdapat titik temu landasan paradigmatik antara empat indikator moderasi beragama tersebut paralel dengan nilai-nilai pendidikan sosial keberagamaan Islam.
\end{abstract}

Kata Kunci: Pendidikan Sosial Profetik, Islam, Moderasi, Indonesia 


\begin{abstract}
The ongoing cases of radicalism and terrorism in the name of religion in Indonesia necessitate the importance of objectifying moderate religious social values. This study aims to identify the values of Islamic religious social education in religious moderation indicators formulated by the Ministry of Religion of the Republic of Indonesia. This research center uses a normative-philosophical approach with analytical theory in the form of a Prophetic Social Science paradigm that was initiated by Kuntowijoyo. The results of the study show that there are social values of Islamic religiosity in the four indicators of religious moderation. First, the transcendence value in tolerance education is in the form of forming social mindsets and attitudes, both in the context of inter-religious and intra-religious life. Second, the value of humanization in national commitment education and accommodative to local culture in the form of forming mindsets and attitudes to maintain nationalism and plural local wisdom. Third, the value of liberation in anti-radicalism education in the form of forming a productive mindset and attitude in realizing a safe and peaceful life. The theoretical implication of this finding shows that there is a meeting point of the paradigmatic basis between the four indicators of religious moderation and the parallel values of Islamic religious social education.
\end{abstract}

Keywords: Prophetic Social Education, Islam, Moderation, Indonesia

\title{
A. PENDAHULUAN
}

Merespons ragam radikalisme dan terorisme atas nama agama di Indonesia yang seringkali dikaitkan dengan motif agama (Zakiyah, 2016:19), Kementerian Agama Republik Indonesia (Kemenag RI) pada tahun 2019 mengeluarkan buku dengan judul "Moderasi Beragama". Melalui buku tersebut, Kemenag RI merumuskan empat indikator yang dapat menjadi tolak ukur dalam menentukan pola pikir dan sikap beragama yang moderat di Indonesia. Empat indikator tersebut, antara lain komitmen kebangsaan, toleransi, anti-kekerasan, dan akomodatif terhadap kebudayaan lokal (Tim Penyusun Kementerian Agama RI, 2019:42-43).

Terlepas dari empat tolak ukur moderasi beragama di atas, penting upaya kesadaran bersama seluruh elemen masyarakat dalam pembentukan karakter sikap sosial keberagamaan individu yang moderat, yakni tidak ekstrem kiri maupun kanan dalam paham dan sikap sosial keberagamaannya (Dodego \& Witro, 2020:199). Orientasi demikian setidaknya dapat diwujudkan melalui objektifikasi nilai-nilai pendidikan sosial keberagamaan yang mengacu pada nilai-nilai sosial profetik dalam ajaran agama. Sebagai contoh dalam ajaran Islam misalnya, terdapat nilai-nilai sosial keberagamaan Islam yang dapat diobjektifikasikan dalam mewujudkan sikap moderasi beragama dalam konteks kehidupan universal. Dalam hal ini, Kuntowijoyo menyatakan terdapat tiga pilar nilai sosial profetik Islam yang dapat menjadi basis paradigma sosial keberagamaan Islam dalam kehidupan universal, antara lain humanisasi (amar makruf), liberasi (nahi munkar), dan transendensi (iman) (Muttaqin, 
2015:221-222). Berbagai etika sosial profetik Islam tersebut seyogyanya diharapkan dapat menjadi landasaan nilai-nilai pendidikan sosial keberagamaan Islam dalam mewujudkan karakter individu yang moderat dalam kehidupan masyarakat Indonesia yang majemuk (Sudjito, et al., 2018:69).

Penelitian kualitataif ini bertujuan untuk mengidentifikasi nilai-nilai pendidikan sosial keberagamaan Islam dalam konstruksi empat indikator moderasi agama yang dirumuskan Kemenag RI dalam buku Moderasi Beragama. Buku tersebut diterbitkan oleh Badan Litbang dan Diklat Kementerian Agama RI pada tahun 2019. Pendekatan penelitian ini menggunakan pendekatan normatif-filosofis, teori analisis yang digunakan, yakni tiga pilar nilai dalam paradigma ilmu sosial profetik yang dicetuskan Kuntowijoyo berupa humanisasi (amar makruf), liberasi (nahi munkar), dan transendensi (iman). Tiga pilar nilai tersebut akan digunakan untuk mengidentifikasi nilai sosial keberagamaan Islam pada empat indikator moderasi beragama yang berupa toleransi, komitmen kebangsaan, antikekerasan, dan akomodatif terhadap kebudayaan lokal.

Penulis menyadari terdapat berbagai penelitian yang memiliki keterkaitan dengan objek pembahasan penelitian ini, antara lain, Mohamad Fahri dan Ahmad Zainuri (2019) menyatakan radikalisme atas nama agama dapat dibasmi melalui pendidikan Islam yang moderat dan inklusif (Fahri \& Zainuri, 2019:95). Paralel dengan Fahri dan Zainuri, penelitian Agus Akhmadi (2019) mengatakan dalam kehidupan multikultural dibutuhkan pemahaman keaneragaman yang menghargai pluralitas (Akhmadi, 2019:45). Selanjutnya, Umma Farida (2020) menuturkan sosok Kiai Hasyim Asy'ari (pendiri Nahdhotul Ulama) berkontribusi besar dalam menyatukan umat Islam Indonesia khususnya, dan masyarakat Indonesia umumnya melalui pembentukan karakter sikap dan pemahaman Islam moderat (Farida, 2020:311-312). Berikutnya, Sumarto (2021) mengatakan moderasi beragama sebagai paradigma dan sikap keberagamaan yang tidak berada pada ideologi radikalisme maupun liberalism (Sumarto, 2021:10).

Berbeda dengan berbagai penelitian di atas, penelitian ini berfokus untuk mengidentifikasi dimensi nilai-nilai pendidikan sosial keberagamaan Islam dalam empat penanda moderasi beragama di Indonesia yang dirumuskan oleh Kemenag RI. Penelitian ini diharapakan dapat mengungkap ada atau tidaknya titik temu paradigmatik antara empat indikator moderasi bergama dengan nilai-nilai pendidikan sosial keberagamaan Islam. Di samping itu, diharapkan juga dapat memberikan pencerahan pada kelompok umat Islam ekstrem kanan yang cenderung skeptis bahkan resistan terhadap norma-norma sosial negara yang secara simbolik tidak menunjukan syariat Islam. Fokus dan orientasi tersebutlah yang mungkin dapat menjadi distingsi sekaligus novelty (kebaruan) penelitian ini dari berbagai penelitian sebelumnya.

\section{B. ILMU SOSIAL PROFETIK (ISP): BASIS PARADIGMATIK PENDIDIKAN SOSIAL KEBERAGAMAAN ISLAM DALAM KEHIDUPAN MAJEMUK}

Eksistensi nilai pendidikan Islam tidak dapat dilepaskan dari agenda misi pendidikan untuk membentuk manusia sehingga mampu menghormati 
tingkah laku manusia serta mempunyai dorongan kerohanian (Arifuddin, 2019:322-323). Untuk mencapai orientasi tersebut dibutuhkan landasan paradigmatik yang memiliki landasan normatif teologis dalam ajaran Islam. Pada konteks inilah, Kuntowijoyo (1943-2005) merupakan seorang cendikiawan muslim Indonesia yang dikenal berupaya menawarkan konsep Ilmu Sosial Propetik (ISP). Melalui gagasan ISP, Kuntowijoyo berharap dapat menghubungkan ketidakseimbangan antara keberadaan ilmu sosial sekuler dan ilmu sosial Islam (Islamy \& Istiani, 2020:177). Gagasan ISP inilah seyogyanya dapat menjadi landasan paradigmatik dari nilai pendidikan sosial keberagamaan Islam dalam konteks kehidupan yang plural, seperti halnya di Indonesia.

Perlu diketahui bahwa gagasan ISP menekankan keberadaan ilmu-ilmu sosial menduduki pondasi dasar untuk menggapai target yang dituju. Dalam hal ini, gagasan ISP menetapkan tiga nilai utama dalam pola yang terstruktur, diantaranya nilai humanisasi (amar makruf), nilai liberasi (nahimunkar), dan transendensi (iman). Ketiga nilai tersebut semestinya bermula dari tiga nilai ajaran Islam yang terkandung dalam Qur'an surat Ali Imran ayat 110 (Muttaqin, 2015:221-225). Penjelasan tiga nilai utama tersebut dapat dipaparkan sebagai berikut;

Pertama, nilai humanisasi. Asas nilai humanisasi (humanisme) ini berakar dari ajaran Islam berupa amar makruf (Muttaqin, 2015:225). Terkait makna term makruf, Abdul Karim Sheikh menuturkan bahwa kata "makruf" memiliki arti yang kompleks, meliputi kebajikan, kebenaran, keadilan, dan pengabdian (Syeikh, 2019:19). Berdasarkan nilai humanisasi ini, Kuntwijoyo bermaksud menggugah manusia untuk dapat memperhatikan keberadaan perintah Tuhan dalam segala aspek kehidupan manusia. Atas dasar itulah, peradaban manusia tidak hanya dilihat pada tataran rasional, tatapi juga menekankan nilai-nilai transendental yang bersumber dari ajaran agama (Islam).

Kedua, nilai liberasi. Eksistensi nilai liberasi pada gagasan ISP merupakan nilai yang berakar dari penafsiran atas ajaran Islam yang berupa nahi munkar (Muttaqin, 2015:226). Abdul Karim Sheikh juga memaparkan sejatinya istilah munkar tidak bermakna sebagai tindakan yang dikekang oleh ajaran Islam, melainkan juga bersumber pada berbagai tindakan yang melanggar akal sehat dan keberadaan budaya manusia (Syeikh, 2019:19). Nilai liberasi ini memiliki empat tujuan utama; 1) upaya mentoleransi umat manusia dari pemikiran duniawi serta memisahkan tingkatan sosial dan gender; 2) upaya mentoleransi sistem sosial dari pengaruh buruk maskapa sosial; 3) untuk mentoleransi sistem ekonomi yang berpengaruh buruk dalam kehidupan manusia; dan 4) upaya mentoleransi sistem politik dari kekuasaan yang totaliter (Abidin, 2016:157).

Ketiga, nilai transendensi. Asas nilai tarsendensi dalam gagasan ISP tidak lain adalah keimanan (iman) yang menjadi dimensi utama ajaran Islam (Muttaqin, 2015:227-228). Oleh sebab itu, nilai transendensi sejatinya bersumber pada pondasi utama dari pandangan sosial profetik humanisasi dan liberasi. Dengan kata lain, nilai-humanisasi, liberasi dan transendensi merupakan tiga sumber nilai yang terpenting dari pandangan ISP yang saling berhubungan sebagai pondasi ke-Islaman pada kehidupan sosial (Maskur, 2012:127). 
Objektifikasi nilai-nilai sosial profetik Islam dalam konteks kehidupan majemuk sebagaimana uraiain di atas sangat relevan dengan penuturan Nurcholish Madjid (Cak Nur). Menurut Cak Nur, universalisme Islam merupakan ajaran universal ramatan lil alamïn (Islamy, 2021b:114). Apa yang disampaikan Cak Nur relevan dengan pandangan Abdurrahman Wahid (Gus Dur) yang menyatakan bahwa Islam merupakan ajaran wahyu terakhir yang berlaku secara menyeluruh. Menurut Gus Dur, universalisme Islam tersebut tidak hanya terletak dari berbagai segi ajaran, tidak terkecuali pada prinsip ajaran yang menekankan nilai keadilan, kemashlahatan, dan keluwesannya dalam menjawab dinamika perkembangan zaman dan berbagai masalahnya (Islamy, 2021a:61). Atas dasar inilah, maka tidak mengherankan jika eksistensi ajaran Islam bukan sekedar menekankan keimanan yang benar, melainkan juga bagaimana ajaran Islam tersebut dapat dimanifestasikan dalam berbagai aspek kehidupan, tidak terkecuali dalam konteks kehidupan sosial yang plural (Aziz, 2013:253).

Pada penelitian ini, tiga nilai ISP tersebut akan digunakan sebagai teori analisis untuk mengelompokan dimensi nilai pendidikan sosial keberagamaan Islam pada empat indikator moderasi bergama yang dirumuskan oleh Kemenag RI.

\section{DIMENSI NILAI PENDIDIKAN SOSIAL PROFETIK DALAM INDIKATOR MODERASI BERAGAMA DI INDONESIA}

Kendatipun pemerintahan Indonesia senantiasa mencanangkan pelbagai program dalam pemberantasan radikalisme maupun terorisme, namun tindakan radikalisme maupun terorisme atas nama agama tidak kunjung usai. Terlepas dari ragam bentuk aksi radikalisme maupun terorisme yang ada, penting disadari aksi tersebut bukan manifestasi tindakan yang tanpa dasar atau motivasi yang melatarbelakanginya, melainkan memiliki landasan paradigmatik (pola pikir) atas interpretasi keagamaan yang diyakninya (Asrori, 2019:118-119). Di sinilah pentingnya penanaman nilai-nilai pendidikan yang dapat mengantarkan pada karakter individu yang moderasi beragama dalam diri individu masyarakat Indonesia.

Keberadaan ajaran Islam seyogyanya mempunyai berbagai nilai ajaran sosial keberagamaan yang kompatibel dalam mewujudkan karakter individu yang moderat (Nugraha, 2012:12). Berbagai nilai ajaran tersebut dapat diobjektifikasikan dalam konteks kehidupan sosial yang majemuk. Pada konteks inilah, Kuntowijoyo dalam ide Ilmu Sosial Profetik yang digagaskannya berupaya menunjukan tiga pilar nilai ajaran Islam yang dapat digunakan sebagai pondasi paradigmatik dalam kehidupan sosial profetik. Tiga pilar nilai ajaran Islam berupa nilai humanisasi, liberasi dan transendensi.

Pada sub bab pembahasan inti inilah, akan diuraikan analisis penulis terkait identifikasi atas dimensi nilai-nilai sosial profetik Islam dalam empat indikator moderasi beragama di Indonesia yang dirumuskan oleh Kemenag RI. Uraian lebih lanjut sebagai berikut. 


\section{Nilai Transendensi Dalam Pendidikan Toleransi}

Toleransi menekankan pentingnya paradigma sekaligus sikap terbuka dalam menghormati dan menghargai sekaligus menerima perbedaan sebagai fakta alam (sunnatullah). Oleh sebab itulah, toleransi menjadi pondasi yang sangat urgen dalam mewujudkan tatanan masyarakat demokrasi di Indonesia. Hal demikian disebabkan sistem demokrasi hanya dapat terealisasi ketika antar individu (kelompok) di dapat saling bersikap toleransi. Dengan kata lain, semakin tinggi toleransi terhadap perbedaan dalam suatu negara (bangsa), maka akan dapat semakin demokratis. Begitu juga sebaliknya (Tim Penyusun Kementerian Agama RI, 2019:44).

Indikator toleransi dalam kehidupan moderasi beragama di Indonesia menekankan intensitas toleransi antaragama dan toleransi intra agama, baik terkait aspek kehidupan sosial maupun politik. Penanaman nilai pendidikan toleransi tersebut dapat diwujudkan dalam pembentukan pola pikir dan sikap sosial yang dilandasi oleh semangat toleransi beragama. Oleh karena itu, melalui sikap toleransi dalam relasi antar umat beragama yang berbeda agama diharapkan dapat terwujud ketersediaan sikap saling berdialog, bekerja sama di antara mereka dalam konteks kehidupan sosial. Sedangkan toleransi intra agama (seagama) diharapkan dapat merespons secara bijak terhadap pelbagai sekte (aliran) minoritas yang dinilai menyimpang dari arus utama (besar) dalam komunitas agama tertentu (Tim Penyusun Kementerian Agama RI, 2019:45).

Dalam perspektif paradigma Ilmu Sosial Profetik (ISP), nilai pendidikan toleransi antar agama maupun intra agama dapat disandarkan pada upaya interpretasi ajaran nilai sosial profetik Islam berupa nilai transendensi (keimanan). Di mana transendensi tersebut menekankan sikap keimanan dalam sikap sosial keberagamaan. Pada konteks ini, dimensi nilai transendensi dalam pendidikan toleransi dapat mengacu pada ajaran Islam yang dapat diobjektifikasikan dalam konteks kehidupan yang majemuk. Nilai pendidikan toleransi tersebut dapat ditemukan dalam berbagai landasan normatif teologis Islam, yang meliputi al-Qur'an surat al-Baqarah ayat 256 yang berbunyi "La ikraha fi al-din qod tabayyana al-rusydu minal ghoyyi" (tidak ada paksaan dalam memeluk agama. Sungguh telah jelas antara kebenaran dan kesesatan). Dengan demikian dapat dikatakan bahwa ajaran Islam menghormati hak hidup agama lain, dan memberikan ruang (mempersilahkan) mereka untuk menjalankan ajarannya (Ghazali, 2016:36).

Dalam sejarah kehidupan Nabi Muhammad saat hidup juga dapat dilihat dari besarnya sikap keterbukaan yang dicontohkan Nabi, para sahabat dan keturunan setelahnya, baik terhadap sesama muslim maupun non muslim. Sebagai contoh sikap keterbukaan Nabi dan kasih sayangnya yang ditujukan kepada non Muslim dapat dilihat dari pelayanan beliau terhadap golongan kafir dzimmi yang hidup di bawah pemerintahan Islam. Dalam hal ini, Nabi pernah bersabda: "Ketahuilah, orang yang menzalimi dzimmi atau mengurangi hak-haknya atau membebankan pekerjaan diluar kesanggupannya atau mengambil sesuatu darinya tanpa kerelaannya, maka aku akan menjadi lawannya pada hari kiamat”. (HR. Abu Daud) (M. Jakfar, 2016:60-61). 
Dimensi nilai transendensi atas nilai pendidikan toleransi di atas seyogyangya dapat menjadi basis nilai pendidikan dalam melahirkan sikap moderasi beragama di Indonesia. Terlebih fakta empiris di Indonesia, terdapat adanya berbagai agama yang diakui di Indonesia yang meliputi Islam, Protestan, Katolik, Hindu, Budha, dan Konghucu, meniscayakan kesadaran sikap umat Islam di Indonesia untuk mengedepankan sikap toleransi terhadap eksistensi komunitas agama lain (non Islam) (Wandani \& Dewi, 2021:36). Oleh karena itu, nilai pendidikan toleransi dapat dimanifestasikan dalam menghargai dan menghormati otoritas hak yang dimiliki setiap umat bergama untuk mengikuti dan menjalankan kewajiban agamanya tanpa adanya paksaan maupun intimidasi dari pihak manapun.

\section{Nilai Humanisasi Dalam Pendidikan Komitmen Kebangsaaan Dan Akomodatif Terhadap Budaya Lokal}

Komitmen kebangsaan dan akomodatif terhadap budaya lokal menjadi bagian indikator terpenting untuk diamati sehingga berpengaruh pada pola pikir, perilaku, dan tindakannya. Keberagamaan seseorang terkait kesetiaannya terhadap konsensus dasar kebangsaan dan kesediaanya menerima ragam keraifan lokal sebagai bagian dari hukum alam.

Tidak dipungkiri bahwa komitmen kebangsaan juga penting dijadikan sebagai indikator sekaligus nilai pendidikan dalam pembentukan sikap moderasi beragama. Dalam hal ini, nilai pendidikan komitmen kebangsaan diharapkan dapat menjadikan individu yakni mengimplementasikan ajaran agama sama halnya dengan melaksanakan tugas sebagai warga negara. Dengan kata lain, melaksanakan tugas sebagai warga negara merupakan manifestasi dari implementasi ajaran agama itu sendiri (Tim Penyusun Kementerian Agama RI, 2019:43-44).

Jika dilihat dalam tinjauan paradigma Ilmu Sosial Profetik (ISP), nilai pendidikan berupa komitmen kebangsaan dalam mewujudkan sikap moderasi beragama dapat dikatakan sejalan dengan nilai humanisasi (amar makruf). Hal demikian dikarenakan komitmen kebangsaan memuat nilai akan pentingnya ikatan persatuan dan kesatuan ditengah kehidupan sosial masyarakat Indonesia yang majemuk (Adha \& Susanto, 2020:136). Terlebih di era globalisasi dewasa ini di mana arus paham dari luar (internasional) berpotensi besar masuk ke Indonesia, baik itu paham yang positif maupun paham yang justru kontra-produktif dengan semangat nilai-nilai kebangsaan atau ideologi negara Indonesia. Pada contoh konteks tersebutlah, pentingnya objektifikasi nilai-nilai pendidikan komitmen kebangsaan dalam mewujudkan sikap moderasi beragama dengan maksud agar setiap warga negara dapat menjunjung tinggi nilai-nilai kesatuan dan persatuan dalam bingkai kehidupan bernegara.

Dimensi nilai humanisasi juga dapat dilihat dalam indikator moderasi beragama berupa sikap akomodatif terhadap budaya lokal. Keberadaan sikap akomodatif terhadap tradisi lokal tersebut dapat menjadi nilai pendidikan untuk membentuk karakter individu dalam menerima ragam praktik keberagamaan yang akomodatif yang identik dengan kebudayaan (tradisi) lokal yang ada di Indonesia. Pada konteks inilah, nilai pendidikan yang akomodatif dengan adat istiadat sangat didambakan sehingga dapat 
membentuk pola pikir dan sikap moderasi beragama individu yang ramah dalam merespons kebiasaan dalam membentuk tingkah laku keberagamaan selama tidak menyimpang dengan ajaran pokok agama tertentu (Tim Penyusun Kementerian Agama RI, 2019:46-47).

Uraian di atas menunjukan bahwa, baik nilai pendidikan komitmen kebangsaan maupun akomodatif terhadap budaya lokal, keduanya memiliki titik temu paradigmatik yang kuat sebagai manifestasi nilai humanisasi (amar makruf). Pernyataan demikian tidaklah berlebihan, dikarenakan term ma'ruf sebagai basis landasan nilai humanisasi dalam paradigm ISP sendiri sejatinya memiliki berbagai arti, diantaranya yakni sebuah kebaikan, keutamaan, kebenaran, keadilan, kelayakan, pantas, patut, bakti, dan lain sebagainya (Syeikh, 2019:19).

\section{Nilai Liberasi Dalam Pendidikan Anti Radikalisme}

Latar belakang terjadinya radikalisme (kekerasan) moderasi beragama diartikan sebagai ideologi yang mempunyai maksud agar dapat merubah sistem sosial dan politik di Indonesia melalui pelbagai bentuk kekerasan yang mengatasnamakan agama, melalui kekerasan verbal, fisik maupun pikiran (Tim Penyusun Kementerian Agama RI, 2019:45). Pada umumnya, kelompok radikal membidik transformasi secara singkat meskipun harus berbenturan dengan sistem sosial yang sudah berlangsung di suatu negara (wilayah). Radikalisme ini juga kerapkali diidentikan dengan terorisme. Hal demikian dikarenakan kelompok radikal dapat memenuhi pelbagai bentuk dan gaya apapun agar impiannya dapat tercapai, termasuk mengancam pihak yang tidak seideologi dengan mereka. Terlepas dari itu, penting juga untuk dipahami bahwa radikalisme tidak hanya dapat terjadi bagi individu atau kelompok agama tertentu, melainkan dapat terjadi di seluruh agama (Tim Penyusun Kementerian Agama RI, 2019:45-46).

Pentingnya keberadaan sikap anti radikalisme sebagai bagian dari indiktaor moderasi beragama di Indonesia dapat menjadi nilai pendidikan dalam pembentukan sikap moderasi beragama yang paralel dengan misi nilai liberasi yang menjadi bagian pilar dari paradigma Ilmu Sosial Profetik (ISP). Ide besar dalam gagasan nilai liberasi merupakan kekuatan ajaran Islam terkait keberagamaan sosial yang didasarkan pada perintah ajaran Islam berupa nahi munkar (mencegah kemunkaran) (Muttaqin, 2015:226). Oleh karena itu, nilai pendidikan anti radikalisme memiliki titik temu landasan paradigmatik nilai liberasi dalam upaya untuk menghilangkan segala bentuk tindakan kemungkaran dan keonaran yang dapat menciderai keharmonisan dalam kehidupan sosial. Dalam tataran ini, nilai liberasi menurut Kuntowijoyo dapat dikatakan bahwa paradigma ilmu sosial profetik bertujuan supaya manusia dapat menghendaki pelbagai perilaku yang intensif terhadap pelbagai bentuk kebatilan, ketidakadilan, dan lain sebagainya (Maskur, 2012:127).

Pengejawantahan nilai liberasi dalam nilai pendidikan anti radikalisme dapat dikorelasikan dengan berbagai nilai ajaran Islam yang kompatibel dengan semangat moderasi beragama, antara lain sikap tawazun (keseimbangan), i’tidal (tegas), tasamuh (toleransi), musawah (kesetaraan), syura (musyawarah), ishlah (reformasi), aulawiyah 
(prioritas), tathawwur wa ibtikar (dinamis dan inovatif) (Fahri \& Zainuri, 2019:95). Berbagai nilai ajaran Islam tersebut seyogyanya dapat menjadi instrument dalam manifestasi nilai pendidikan anti radikalisme dalam mewujudkan mewujudkan kehidupan sosial majemuk yang aman dan damai.

Keberadaan dimensi nilai sosial profetik Islam dalam nilai pendidikan yang dapat membentuk karakter individu yang moderat dalam berfikir dan bersikap sosial di atas menunjukan bahwa sejatinya indikator moderasi beragama di Indonesia yang dirumuskan oleh Kemenag RI memiliki relevansi paradigmatik yang kuat dari nilai-nilai sosial keberagamaan Islam. Hal ini juga menunjukan bahwa Islam merupakan petunjuk agama yang memiliki nilai-nilai universal dalam mewujudkan kemaslahatan hidup uamat manusia.

\section{KESIMPULAN}

Berdasarkan pembahasan inti penelitian ini dapat disimpulkan bahwa terdapat nilai-nilai sosial keberagamaan Islam dalam empat indikator moderasi beragama di Indonesia yang dirumuskan oleh Kementrian Agama Republik Indonesia (Kemenag RI). Pertama, nilai transendensi dalam pendidikan toleransi berupa pembentukan pola pikir dan sikap sosial, baik dalam konteks kehidupan antar umat beragama maupun intra agama. Kedua, nilai humanisasi dalam pendidikan komitmen kebangsaan dan akomodatif terhadap budaya lokal berupa pembentukan pola pikir dan sikap menjaga nasionalisme dan kearifan lokal yang majemuk. Ketiga, nilai liberasi dalam pendidikan anti radikalisme berupa pembentukan pola pikir dan sikap yang produktif dalam mewujudkan kehidupan yang aman dan damai.

Implikasi teoritik temuan penelitian ini dapat menunjukan bahwa terdapat titik temu landasan paradigmatik dalam empat indikator moderasi beragama yang dirumuskan Kemenag RI dengan nila-nilai pendidikan sosial keberagamaan Islam berupa nilai humanisasi (amar makruf), dan liberasi (nahi munkar), dan transendensi (iman). Hal ini juga menunjukan bahwa kendatipun narasi empat indikator moderasi beragama yang dirumuskan Kemenag RI secara simbolik tidak menunjukan simbol (label) Islam, akan tetapi secara substansi memiliki landasan nilai dengan nilai-nilai pendidikan sosial keberagamaan Islam.

Terdapat lacuna (ruang kosong) penelitian ini yang dapat dijadikan fokus oleh peneliti lain pada penelitian berikutnya, yakni terkait bagaimana pola atau strategi Kemenag RI dalam pengejawantahan empat indikator moderasi beragama yang dirumuskannya dalam konteks sistem pendidikan Islam di Indonesia. 


\section{REFERENSI}

\section{Buku (Kitab)}

Abidin, M. Z. (2016). Paradigma Islam Dalam Pembangunan Ilmu Integralistik: Membaca Pemikiran Kuntowijoyo. IAIN Antasari.

Tim Penyusun Kementerian Agama RI. (2019). Moderasi Beragama. Badan Litbang dan Diklat Kementerian Agama RI Gedung Kementerian Agama RI.

\section{Tesis, Disertasi}

Islamy, A. (2021b). Pemikiran Hukum Islam Nurcholish Madjid. Universitas Islam Negeri Walisongo.

Maskur, M. (2012). Ilmu Sosial Profetik Kuntowijoyo (Telaah atas Relasi Humanisasi, Liberasi dan Transendensi). UIN Alauddin Makassar.

\section{Jurnal dan lainnya}

Adha, M. M., \& Susanto, E. (2020). Kekuatan Nilai-nilai Pancasila dalam Membangun Kepribadian Masyarakat Indonesia. Al-Adabiya: Jurnal Kebudayaan Dan Keagamaan, 15(01), 121-138. https://doi.org/10.37680/adabiya.v15io1.319

Akhmadi, A. (2019). Moderasi Beragama Dalam Keragaman Indonesia. Inovasi: Jurnal Diklat Keagamaan, 13(2), 45-55. Retrieved from https://bdksurabaya.e-journal.id/bdksurabaya/article/view/82

Arifuddin, A. (2019). Konsep Pendidikan Profetik (Melacak Visi Kenabian Dalam Pendidikan). Jurnal Mudarrisuna: Media Kajian Pendidikan Agama Islam, 9(2), 319-338. https://doi.org/10.22373/jm.v9i2.4782

Asrori, S. (2019). Mengikuti Panggilan Jihad; Argumentasi Radikalisme Dan Ekstremisme Di Indonesia. AQLAM: Journal of Islam and Plurality, 4(1), 118-133. https://doi.org/http://dx.doi.org/10.30984/ajip.v4i1.911

Aziz, D. K. (2013). Akulturasi Islam dan Budaya Jawa. Fikrah: Jurnal Ilmu Aqidah Dan Studi Keagamaan, 1(2), 253-286. https://doi.org/http://dx.doi.org/10.21043/fikrah.v1i2.543

Dodego, S. H. A., \& Witro, D. (2020). The Islamic Moderation And The Prevention Of Radicalism And Religious Extremism In Indonesia. Dialog, 43(2), 199-208. https://doi.org/10.47655/dialog.v43i2.375

Fahri, M., \& Zainuri, A. (2019). Moderasi Beragama di Indonesia. Intizar, 25(2), 95-100. https://doi.org/https://doi.org/10.19109/intizar.v25i2.5640

Farida, U. (2020). Kontribusi dan Peran KH. Hasyim Asy'ari dalam Membingkai Moderasi Beragama Berlandaskan al Quran dan Hadis di Indonesia. Fikrah: Jurnal Ilmu Aqidah dan Studi Keagamaan, 8(2), 311328. https://doi.org/10.21043/fikrah.v8i2.7928

Ghazali, A. M. (2016). Toleransi Beragama Dan Kerukunan Dalam Perspektif Islam. Religious: Jurnal Studi Agama-Agama Dan Lintas Budaya, 1(1), 25-40. https://doi.org/https://doi.org/10.15575/rjsalb.v1i1.1360 
Islamy, A. (2021). Landasan Filosofis dan Corak Pendekatan Abdurrahman Wahid Tentang Implementasi Hukum Islam di Indonesia. Jurnal AlAdalah: Jurnal Hukum Dan Politik Islam, 6(1), 51-73. https://doi.org/10.35673/ajmpi.v6i1.1245

Islamy, A., \& Istiani, N. (2020). Aktualisasi Nilai-nilai Profetik dalam Pendidikan Keluarga di Tengah Pandemi Covid-19. Mawa’zz: Jurnal Dakwah Dan Pengembangan Sosial Kemanusiaan, 11(2), 169-187. https://doi.org/10.32923/maw.v11i2.1460

M. Jakfar, T. (2016). Perspektif Al-Quran dan Sunnah tentang Toleransi. Substantia: Jurnal Ilmu-Ilmu Ushuluddin, 18, 55-67. https://doi.org/10.22373/substantia.v18io.8982

Muttaqin, H. (2015). Menuju Sosiologi Profetik. Jurnal Sosiologi Reflektif, 1O(1), 219-240. https://doi.org/10.14421/jsr.v10i1.1147

Nugraha, A. (2012). Moderate Islam as New Identity in Indonesian Foreign Policy: Between Global Role Aspiration and Co-Religious Solidarity. JICSA: Journal of Islamic Civilization in Southeast Asia, 1(1), 12-35. https://doi.org/https://doi.org/10.24252/jicsa.v1i1.712

Sudjito, et.al. (2018). Pancasila And Radicalism: Pancasila Enculturation Strategies As Radical Movement Preventions. Jurnal Dinamika Hukum, 18(1), 69-77. https://doi.org/10.20884/1.jdh.2018.18.1.1686

Sumarto, S. (2021). Implementasi Program Moderasi Beragama Kementerian Agama RI. Jurnal Pendidikan Guru, 3(1), 1-11. https://doi.org/10.47783/jurpendigu.v3i1.294

Syeikh, A. K. (2019). Rekonstruksi Makna Dan Metode Penerapan Amar Ma'ruf Nahi Munkar Berdasarkan Al-Qur'an. Al-Idarah: Jurnal Manajemen Dan Administrasi Islam, 2(2), 1-22. https://doi.org/10.22373/alidarah.v2i2.4009

Wandani, A. R., \& Dewi, D. A. (2021). Penerapan Pancasila Sebagai Dasar Kehidupan Bermasyarakat. De Cive: Jurnal Penelitian Pendidikan Pancasila Dan Kewarganegaraan, 1(2), 34-39. Retrieved from https://journal.actual-insight.com/index.php/decive/article/view/225

Zakiyah, Z. (2016). The Chronicle Of Terrorism And Islamic Militancy In Indonesia. Analisa: Journal of Social Science and Religion, 1(1), 19-40. https://doi.org/10.18784/analisa.v1i1.276 